\title{
A DEMANDA DO SANTO GRAAL
}

Súmula: - A edição de Augusto Magne - características; a edição de Albert Peuphilet - características, O confronto de textos. O probiema da filiação.

A édição integral do texto português de "A Demanda do Santo Graal" sòmente se fêz em 1944, graças aos eșforçcs dispendidos por Augusto Magne durante mais de vinte ancs. Vinha à luz a tão esperada edição em época relativamente tarđia dâdas as dificuldades de ordem vária com que se debateu o seu editor, naturais em emprésas dessa envergadura. Mas enfim, transpondo os obstáculos que pareciam intransponiveis, pôde-se levar a cabo tão árduo trabalhc, enobrecedor das letras portuguèsas e slevada con. uribuição do Brasil à reconstituição dos nosso maiores monumentos do pミssado, na sua maior parte jazendo ainda hoje em austeras e amplas bibliotecas de Portugal.

O que lcgo nos chama a atenção em "A Demanda do Santo Graal" é a divisão em episódios, feita pelo editor, conforme suz afirmação (vol. I, pg., 43, nota 3): "Para torner menos pesada a leitura do romance, repartimo-lo em episódics, introduzidos por competentes titulos". " Os episódios, por sua vez, estão subdivididos em parágrafos, numerados por Augusto Magne e epigrafados na sua maioria: "Dos parágrafes, näo têm epígrafe o primeiro e a maior parte, a partir do número 195" (Vci. I, pg. 433, nota 2). Observa-se geraimente que as epigrafes que aparecem no alto das páginas correspondem às mesmas dos parágrafos. Assim, quanco vários parágraf́os estão correlacionados entre si (todos o estão, mas aqui referímo-nos a uma correlação dramática mais întima, concentrada num único objetivo) - ou se referem a uma só personagem (por ex.: vol. I, pg. 240 - "Persival na ermida"), usa-se uma epigrafe geral. Em raros casos, nctadamente a partir do parágrafo 195, a epígrafe é sugerida pelo texto, visto que o parágrafo não pode fornecê-la. $O^{\prime}$ mesmo se pode dizer dos títulas dos episódics.

Ora, tais particuleridades puramente de ordem técnica, näo correspondem ao códice, como sa pode observar pelo simples exame do fac-simile que acompanta cada volume. Vejarnos em que 
nāo corresponde: o códice contém narraçāo ccrride, isto $\dot{e}_{\text {, não }}$ apresenta aquela divisão em episódios feita por Augusto Magne. Entretanto, apresenta parágrafos na sua maior parte epigrafados e introducidos pot uma uncial que os caracteriza. Conclui-se disso que a único ponto de contacto aparente, formal, gráfico é o que diz respeito aos parágrefos. A divisäo assim em diminutas unidades gráficas talvez corrsspondesse à preocupação do aspecto formal por parte dos copistas, de que nos convenceriamos caso todos as paragrafos tivessem relativannente o mesmo tamanko. Pelo exame do fac-simile observa-se que tal fenomeno näo ocorre: éles variam de tamanho e variam muitio, levando alguns meia cohuna, enquanto outros ocupem duas ou très colunas. Não significa isto que nāo acreditemos na preccupação caligráfica por parte dos copistas, preocupação essa que se evidencia pela própria divisão em parágrafos elegantemente iniciados por unciais. Cremos, porérm, qus, sôbre correspender a preocupaçōes formais, a divisão em parágráos talvez tenha compromisses com a parte propriamente dramátice da novela, quer dizer, é possível que cada parágrafo corresponda também a um momento dramático de todo o drama dos cavaleiros: seria como que ume fração autonoma, integra, dramática e caligraficamente, conquanto intimamente subordinada ao todo e ligeda às outras fraçōes. As epigrafes, por outro lado, colaborariam ta identificeção dos parágrafos. Observa-se ainda que cada folhe comporta duas colunas de texto, como por exempio: Fl. 1, a-b; Fl. 2. a-b, etc. Dentro dos parágrafos os diálogos fazem parte da narrativa comum, nada havendo que os saliente gràficamente - o contexto indicá-lo-á. A separação entre dois periodos - (náo chamamcs parágrafo por evitar confusão) - de um thesmo parágrafo é feita por um simples sinal inclinado, de tal farma que não hé intervalos ou espaços entre o comêço e ofim do parágraf́. A ediçäo de Augusto Magne, todavia bane o sinal inclinsd. e adota todos os recursos modernos para a indicação de diálogos.

Quanto à edição de "La Queste del Saint Graal" atribuída a Crutier Map, realizada pot Albert Pauphilet depois de longo e árduo trabalho, frá que dizer que resulta do confronto de vários textos franceses existentes em bibliotecas da França, Inglaterra e Bélgice (V. Afber! Pauphilet, "Etudes sur La Queste del Saint Graal", pgs. VI a $\mathrm{X}$ ). Depois do contronte entre algumas families de textos. Albert Pauphilet optou por cuas delas, escolheu um grupo de cada família, retirou dos grupos um texto para servir de base à redação \& os demais para serem colacionados. Feita segundo este crìéric, a ediçāo apreserita narraçāo corrida, quer dizer, nẩo se preccupou com a divisáo en episódios, como fêz Augusto Magne, embora possam ser observados alguns intervalos gráficos. Os parágrafos, pot vézes correspondentes acs da ediçāo portuguêse, año são nunnerados nem epizráados, apesat de apresentarem o aspecto autñomo que acreditamos carecterizar os da ediçāo Magne. 
No interior dos parágrafos notemcs os diálogos evidenciados por aspas ou travessão, estando, pois, mais próximos do códice, se se considerar que nesse particular 0 códice português não se afastaria do homônimo francês. As páginas estão encimadas por epigrafes que não sabemos serem do editor ou do códice; quer-nos parecer que já estejam, duma maneira geral, nos códices que Albert Pauphilet compuisoú.

Pois bem. Referíno-nos, lirihas atrás, a certos intervalos grá ficos existentes no texto francês. - Gràficamente se evidenciam por um sinal correspondente a três estrêlas que formam um triângulo equilátero. Seria divisão de Pauphilet, ou do códice? O simples sinal gráfico nada poderia solucionar, mas iria auxiliat-nos no methor conhecimento do probleme. Buscou-se a relação possível entre os intervalos e o texto: de Pauphileks au do códice, seriam arbitrários os intervalcs, seria arbitrária a divisão da novela? Não ccrresponderia a uma divisão intrinseca da mesma?

Chamou-nos a atenção o fato de a cada intervalo corresponder um episódio que começa sempre com a seguinte frase: "Or di li contes que..." (1) e a outro que termina com a frase: "Si lesse cre a tant li contes..." e variantes. Năo seria mera coincidência. porquanto nos 14 intervalcs se observa com precisão $\cdot$ mesmo fenômeno. Mas o problema não estava solucionado; restava constatar a provável relação entre essa divisão gráfica e a coincidência de frases introdutórias e conclusivas. Feito a estudo dos 15 episódios que resultam dêsse fracionamento, verificou-se que cada episódio - dencminando assim a fração de texto entre dues frases "Or di li contes que..." ou entre uma delas e "Si lesse ore a tent li contes..." - apresenta unidade dramática. Estava-se, pois, diante de verdadeircs episódios, considerando-se a sua integridade e o terєm meio, começo e fim: são como que contos ligados entre si e subcrdinados a um tema, cu, para recordar velho costume medieval, assemelhavam-se com aquêles murais das igrejas, expressivos de vida cristã e edificantes da alma humana. De qualquer forma, tratava-se da divisão intrínseca do romance, que não obedeceu à influência do editor, o que vale dizer que os pontos de transição da narrativa estavam assinalados e evidenciados. Se houve influência do editor, Esta constou apenas de indicar gràficamente a divisão intrínseca da novela, os pontos de contacto entre um episódio e outro. Restava verificar se o mesmo não occrre com a versão portuguêsa.

A ediçăo de Magne parecia dificultar a pesquisa, dade a divisão em episódios por êle feita. No entanto, partimos dêstes mesmos, por não haver por cnde partir. Verificamos ao fim da análise de todo o romance que existe também no texto portuguès a trassição acusada pelas frases "Mais ora leixa o conto..." e "Ora diz 
o conto que...", respectivamente no fim e no comêço de cađa fração dramática, correspondendo, pois, quase exatamente ao que ocorre no texto francês. O seu número, porém, assoberbounos: cêtca de 54, incluindo os passos em que falta qualquer uma das frases. Era considerável a diferença. Teria "A Demanda do Santo Graal" 54 episódios convenientemente integrados nos moldes dos 14 da "Queste"? Atraía-nos o pormenor de a frese "Ora diz o conto que..." geraimente iniciar parágrafo. Ora, Augusto Mingne, ao fazer a divisàc em episódios, näo se ateve à frases introdutórie e conclusiva - o que transformaria a sua edição em 54 capítulos, quando apresenta LXXXVIII - embora atentasse no seu papel, conforme se observa pelos vários episódios começados com "Ora diz o conto que..."E o copista medieval, estaria ciente de se tratar duma divisāo intrinseca da narrativa? Estamos conveñcidos que não: usa a frase introdutória - ou porque já está no códice quê copia ou traduz - ou por necessidades de ordem técnica.

Volvando aos textos da ediçấ portuguésa e francesa, ccmo se resolveria o impasse provocado pela diferença de episódios? Tínhamos assente uma coisa: os episódios da edição Pauphilet são autonomos completos. tém integridade. $O$ aumente de frases intredutórias na ediçăo portuguesa significarie aumento de episódios. ou haveria em alguns destes várias frases inirodutórias?

Fomos ao texio poriugués e ao exame do mesmo se póde verificar que, ao ncsso juizc, há cuas sortes de frase introdutória: uma, que introduz episódios gerais em que a figure predominante $\dot{e}$ um cavaleiro, quando muito dois, ainda que haja vários em açăo, e outra, que introduz passagens intermediárias. Em ambos os casos, seja a transição dum episódio geral para outro, seja a introdução duma passagem secundária, um só é o seu papel: introduzir personagens ou cenas: trata-se dum expediente narrativo que se repete à falta doutros recursos por parte do copista ou tradutor que busca em vào quebrar a monotonia através das variantes. $\mathrm{Em}$ certos casos não há frase alguma - especialmente depois do parágrafo 195 (tembramos que a frase "Mais cra ieixa o conto.. ." aparece com freqüéncia en eprigrafe) - como se o calígrafo quisesse levar avarte essá preocupação. Seria tal hábitc, em última análise, uma de-

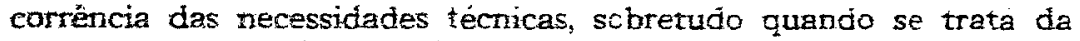
passagem entre dois episódios gerais. Considerando-se assim o problema, reduzia-se sensivelnente o número de intervalos e então já padiamos contar cêrca de 13 episódios bem delineades a completos, giranco quase sempre em tôrao de uma só personagem cujas averzturas são acompanhadas por outras, secundáries, para as quais nāo caberia um episódio especial, porque então a novela se alongaria por várias centeñas de págiras, especiaimente no que diz respeito ao texto portuguess. que conta com númerc elevado de cavaleiros. Nào significa isso que as aventuras da personagem principal estejam todas exfeixadas no episćdio que the é destinado: além do seu epi- 
gódio, aparece em outras aventuras como cavaleiro secundário. Isso nāo impede que uma personagem seja estudada em mais de um episódio especial, ccmo ocorre com Galaaz, a quem sâo dedicados dois enormes capitulos, um de cêrca de 60 páginas (vol. I, pg. 91 a 152) e o outro de mais ou mencs 270 páginas (vol. II, pg. 43 a 316 ), dentro dos quaìs, ccmo consideramos, há uma série de pontos de transição.

Ora, de posse de tais dados já era possivel tentar um confronto entre os textos das duas ediçóes, partindo da divisão intrinseca das novelas. A đúvida era a seguinte: haveria conccrdância intrínseca entre êsses episódios, 'nāo concordância linha a linha, mas dramática?

Os dois textos à frente, iniciamos o confronto. À págin 26 da edição de Pauphilet se encentra o primeiro intervalo, que corresponderia ao da página 91 da edição de Magne. Fizemos o confronto dos dois episódios e verificamos haver correspondência dramática, conquanto formalmente haja lacunas de ambos os ladcs, ou melhor, em mais de um passo o texto português parece apresentar maior número de minúcias, pelo que se poderia dizer que a narração portuguêsa é mais plástica que a francesa, ainda que às vêzes se observe o oposto.

O segundo intervalo está à página 41 da edição francesa e 113 da portuguêsa. Feito o confronto, verificou-se que nos dois episódios há certo equilíbrio, dramático e formal, muito embora haja de vez em quando desencontros de narraçāo, que em nada afetam o conteúdo dramático. Afora isso, estäo bastante próximcs um do outro.

A bem dizer, as divergênciàs maiores, desconcertentes, comsçam do segundo episódio em diante. Tomamos a edição francesa e fizemos o ccnfronto. No terceiro episódio da "Queste" coexistem três momentos dramáticos, dois dos quais enccntram correspondència no episódio português, mas o terceiro - "Le chateau des Pucelles" (pg. 47 a 51) vai corresponder a "Castel Felom" (vol. II, pg. 194). Notemcs que a narração varia dum para outro texto. $E^{\prime}$ preciso que se recorde não continuarmos daqui por diante com 0 confronto episódio a episódio, segundo o que vimos para a ediçăc de Augusto Magne. Estamos partindo da edição francesa para a portuguêsa, considerando os episódios da primeira e confrontandc-os com os da segunda, levando-se em conta uma vez ou outra as transições secundárias. O confronto episódico jamais se faria a partir da segunda, porisso que os episódios da ediçāo portuguêsa são geralmente muito extensos a acompanhados de sucessivas interpolações.

O quarto e o quinto episódios da edição francesa pràticamente não encontram correspondência alguma com o texto poftuguês. Quase o mesmo se pode dizer to sexto episódio (Pauphilet, pg. 71 a 115), dentre o qual uma sís passagem tem correspendente, mas de narrativa sensiveimente divezsa: "Tentation de Perceval" (pgs. 
91 e 105) - e "Tentaçam de Persival" (vol. I, pg. 325). Ainda neste episódic, a pessagem "Perceval chez la recluse" (pg. 73) corresponderia a "Persival em casa de sua tia" (vol. I, pg. 291) talvez por uma frase: - "E Persival olhou e maravilhou-se, quando viu que era empardeada" (vol. I. pg. 291), pois a narrativa é bastante diferente. E possivel que o que melhor se ajustasse fósse "Erec e a empardeada" (vol. I, pg. 382) pela semelhançe de epigrafes, mas - conteúdo narrativo é diferente.

O sétimo episódio apresenta concordâncias e discordâncias.

O oitavo episódio (pg. 147 a 162) contém apreciável semeihança gráfica com a edição de Magne (vol. I, pg. 175 a 214) e nitula correspondência dramática: mesmo que se considere a interpoleção das páginas 175 a 187 , feita entre duas frases introdutória e conclusiva. Lembremos que o mesmo ocorre nos extremos da fração tramática, fato êsse que acresce ainda mais a ccinciọencia episódica.

O nono episódio apresenta semelhanças e dissemelhanças.

O décimo episódio (pg. 195 a 210) encontra certa correspondència no texto portugués, se bem que não seja de passagens ligadas imediatamente entre si. Exemplificando, à passagem "Gralaad blesse Gauvain" (pg. 196) corresponde "Torneic forte e maraviTheso" (vol. I, pg. 331 a 335), enquanto "La Nef Merveilleuse" (pg. 199) corresponde a "A Barca Maravilhosa" (vol. II, pg. 93). Certo, não devemos levar em consideração o fato de a edição de Augustc Magne estar preparada em dois volumes, quando se sabe que o códice apresenta narração corrida. Todavia, acreditamos de. veras considerável a interpolação entre as duas passagens - por volta de. 160 páginas.

O unidécimo episódio - "Legende de l'arbre de la vie" (pg. 210 a 226) não encontra sequer referências no texto português.

$O$ duodécimo episódio (pg. 226 a 244) corresponde com poucas diferenças ao texto preparado por Magne (vol. II, pg. 99 a. 124), sendo que o seu têrmo se dá com atfrase "Mais ora leixa o conto..."

O décimo-terceiro episódio - "Chatiment divin" (pg. 244 a 246) corresponde a "A vingança do Senhor Deus" (vol $\Pi$, pg. 124 a 126) delimitado entre as habituais frases introdutória e conciusiva :

O décimo-quarto episódio (pg. 246 a 262) corresponde relativamente è edicão portuguêsa. (vol. II, pg. 197 a 237), ausentes as frases "Mais ora leixa o conto..." \& "Ora diz o conto..." Há algumas interpolaçöes.

O décomc-quinto episódio (pg. 262 a 280) - último - encontra zitida correspondéncia no texto portugués (vol. II. pg. 275 a 316), com exceção da primeira passagem: "Galaad et le roi Mordraín” (pg. 262). 
- Pelo exposto se pode dizer que há falhas e adições em ambos os lados. A edição de Páphilet apresenta três episódics completamente isolados, mas é pouco em relação às inúmeras passagens do texto portugués sem quaiquer correspondente. Numerosas são as interpolações, aventuras intermediárias ausentes da "Queste", pormenor que está em íntima ligação com o fato de a novela. portuguêsa apresentar maior número de cavaleiros, de tal modo que muitos dêles nem citados são na edição francesa, como Erec,.Palamades, Patrides, Dalides. Ivam de Cenel, rei Mars, para citar apenas alguns. Como se as interpolações e a disparidade do número de cavaleircs não bastassem, desconcerta-nos verificar que - enquanto a edição de Pauphilet termina com a morte de Galaaz, a "Demanda" prossegue, por mais 70 páginas, em que são narrados a morte de rei Artur, as lutas com rei Mars e o episódio Lancelot e a rainha Ginebra.

Pôsto isso, só podemos falar em têrmos de concordâncias e disccrdâncias entre as duas edições - nunca em conicordância e discordância, porquanto nenhum dos dois casos ocorre integralmente no confronto das đuas novelas. Assim colocada a questão, somos levados a pensar no sério problema da filiação: - a "Demanda" portuguésa - aproximando-se e afastando-se em muitos passos da edição francesa - fíitar-se-á a qual dos manuseritos compulsados por Albert Pauphilet?

\section{MASSAUD MOISES}

Pectuarel en Letras Nop-Latinas pela Fincul. didie de Filogofia do Mackenzie.

Bibliografia utilizada:

1. - Magne Augusto. "A Demanda do Santo Graal", 2 vols., Imprensa Nacional, Rio, 1944.

2. - Pauphilet, Albert. "Etudes sur la Queste del Saint Graal", Paris. Librairie Ancienne Honoré Champion. 1.921.

3. - Pauphilet. Albert. "La Queste del Saint Graal", Paris, Librairie Ancienne Honcre Champion. 1949. 